\title{
Tension and relaxation in space-station science
}

\section{Barring accidents, construction of the space station seems inevitable. Obstacles confront those hoping to achieve high-quality research there. There is a continuing need for close monitoring of priorities.}

$\mathrm{D}$ o people have a future in space? This publication has already stated its view that, when it comes to science carried out on planetary surfaces, scientists are best placed in laboratories remote from the action, back on Earth (Nature 388, 211; 1997). There is little sign that the public is much fascinated by astronauts' activities until things start to go wrong. Although there is a role for astronauts in carrying out science on the space station, the significance of that science has been much debated (see Briefing, pages 732-737). Perhaps the only significant reason to worry about human physiology, bone decay and plant growth in zero-gravity is the certainty that sooner or later, space tourism will be upon us.

The space station's rationale and design have both changed more times than its engineers care to remember. The $\$ 8$ billion outpost that President Ronald Reagan proposed in 1984 was to have been part space factory, part laboratory, part astronomical and Earth observatory, and part transportation depot for inbound and outbound spaceships. But when the price increased by an order of magnitude and the number of missions dropped, political support eroded and the station passed a 1993 congressional vote by only one vote. It survived by being recast as a US-Russian alliance, which has presented its own difficulties.

\section{Risks}

The risks inherent in the space station are huge for the National Aeronautics and Space Administration (NASA). Troubled by burgeoning costs that have led to the scaling down of initial plans, the agency still finds itself committed to a daunting technological challenge: 45 launches over the next five years just to assemble the structure, with every reason to expect at least major unforeseen technical problems. Costs can be expected to climb, increasing the station's political vulnerability as Congress and other countries question the wisdom of continuing. And the history of technical megaprojects shows that politicians can be fickle (or, from their view, fiscally responsible) in pulling the plug abruptly, with scant concern that in doing so, huge investments (or, from their view, risky historical spending) will be wasted.

If the space station fails, it could have a chilling effect on large-scale international collaboration - certainly in the space arena, and perhaps elsewhere in science. The idea of sending more astronauts into space could be shelved, because without a station the space shuttle would have no real purpose. And a Mars adventure might be judged unfeasible if, after nearly 15 years of effort, the world's industrialized countries fail to put even a modest shelter for seven people into low Earth orbit.

These are risks that NASA's Administrator, Daniel Goldin, fully understands. For now, however, the space station has strong appeal both at the technological and the more visceral 'vision' level. The idea that Senator John Glenn should go back into space has proved to be attractive to US citizens, however sceptical scientists may be about the claim that it will help us to understand ageing. But such a stunt also reflects a questionable aspect of Goldin's approach: his readiness to cite science as a prime public justification for his activities when, in short, it isn't. In truth, science is a figleaf for the space station's expenditure. Few scientific organizations support the station's science programme, and many have specifically opposed it - even though money saved by the station's cancellation would probably not be bestowed upon science.

\section{Harm}

There is potential harm to be done by using questionable science to sell a project that otherwise might not pass muster. It confuses a public already struggling to distinguish between scientific consensus and junk claims. It makes it more difficult for space-based experimenters some of whom are doing interesting, if highly esoteric, basic research — to be taken seriously by their colleagues. And it risks increasing disenchantment with science if it fails.

Admittedly, once the costs of supporting and transporting experiments into orbit are factored out, the money spent on microgravity research itself is small. And whatever one thinks of the search for antimatter, the study of dendritic structures in crystals, or the accuracy of atomic clocks (all planned experiments), the figleaf is important enough for their future to be assured in principle. But, in practice, scientists have good cause to worry.

There are already signs that space station science will not get the support researchers need to fulfil their ambitions. Some science is withering through the sheer delay in the space station schedule. Some is threatened by shortcomings in the design of the space station facilities. Another problem is that European classic: finding the money in domestic science budgets to be able to benefit scientifically from the large financial investment in facilities. Finally, quality time from the astronauts may be in short supply.

NASA — and, to a lesser extent, its partners - needs to assure scientists that this time, their basic needs will be met. On the space shuttle, scientists were promised that onboard facilities such as computers and telecommunications would be upgraded once the vehicle proved itself. But the money for such improvements never materialized, and solutions to financial or logistical problems often came at the expense of science. This tension between space-based researchers and their landlords will bear close watching.

So much for researchers involved in the space station. But what happens to others when, as they surely will, space station costs continue to soar? In the past, space science budgets have been raided. Astronomers and already beleaguered Earth-observers have good cause to anticipate further encroachments, even though the scrutiny of Congress provides some level of protection against such collateral damage.

But, barring a technological or economic catastrophe, the political and institutional momentum makes the space station unstoppable, while the US science budget is set to increase anyway. The community has placed its negative scientific judgements of the station on the record; they will have no need to feel embarrassed if the pickings are slim, and can join in the celebrations if they aren't. Whatever our feelings about the initial decision, the best the rest of us can do is relax and enjoy the spectacle. 